\title{
DETERMINANTES PARA UTILIZAÇÃO DE HEDGE ACCOUNTING: UM ESTUDO EMPÍRICO EM COMPANHIAS BRASILEIRAS LISTADAS NO SEGMENTO NOVO MERCADO DA BM\&FBOVESPA
}

DETERMINANTS FOR THE USE OF HEDGE ACCOUNTING: AN EMPIRICAL STUDY IN BRAZILIAN COMPANIES LISTED IN THE SEGMENT NEW MARKET OF BM \& FBOVESPA

VANDO DA CONCEIÇÃO ROSAS

Universidade do Estado do Rio de Janeiro

RODRIGO DE OLIVEIRA LEITE

Universidade do Estado do Rio de Janeiro

GUILHERME TEIXEIRA PORTUGAL

Universidade do Estado do Rio de Janeiro

Recebido em 03/05/18

Avaliado pelo sistema double blind review e solicitado revisões em 17/05/18

Aceito para publicação pelo Editor Chefe Dr. Leonardo José Seixas Pinto em 01/06/18 e publicado em 20/06/18

\section{RESUMO}

Este estudo tem como principal objetivo verificar se determinantes como "tamanho" e "dívida" são capazes de influenciar as companhias brasileiras do segmento do Novo Mercado a adoção do Hedge Accounting. Com o intuito de atingir os objetivos propostos, realizou-se uma pesquisa descritiva, uma vez que descreveu fenômenos e experimentos realizados no estudo de natureza quantitativa por utilizar técnicas estatísticas para classificar e quantificar dados extraídos da amostra. A amostra inicial foi composta por 91 companhias do segmento de Novo Mercado da BOVESPA. Verificou-se ainda que a variável relacionada ao faturamento está diretamente associada a escolha contábil, diferente das variáveis associadas as dívidas que afastam a adoção desta metodologia. Observou-se ainda que, apesar dos altos níveis de exigências apresentadas por empresas de auditorias classificadas como uma das Big Four, não serviu como fator influência para a aplicação do Hedge Accounting. Desta forma, com base nos dados gerados nesta pesquisa, entende-se que "tamanho" e "dívida" não são fatores exclusivamente fortes e determinantes para adoção da contabilidade de Hedge para as companhias brasileiras.

Palavras chaves: Hedge Accounting; Derivativo; Contabilização.

\section{ABSTRACT}

This study has as main objective to verify if determinants like "size" and "debt" are able to influence the Brazilian companies of the New market segment the adoption of Hedge Accounting. In order to reach the proposed objectives, a descriptive research was carried out, since it described phenomena and experiments carried out in the quantitative study by using statistical techniques to classify and quantify data extracted from the sample. The initial sample consisted of 137 publicly-traded companies that published their financial statements for the year 2016 and from this all the companies that did not have active derivative contracts in the year surveyed were extracted. Thus, only 91 companies from this segment were considered as the sample basis of study. It was also verified that the variable related to the billing is directly associated to accounting choice, different from the variables associated with the debts that distance the adoption of this methodology. It was 
also observed that, despite the high levels of requirements presented by auditing companies classified as one of the Big Four, it did not serve as an influencing factor for the application of Hedge Accounting. Thus, based on the data generated in this research, it is understood that "size" and "debt" are not exclusively strong and determinant factors for adopting Hedge accounting for Brazilian companies.

Keyboards: Hedge Accounting; Derivative; Accounting.

\section{INTRODUÇÃO}

Com o crescimento da competitividade entre as organizações devido a globalização, muitas empresas recorreram a mecanismos conhecidos como derivativos com o intuito de proteger suas transações financeiras e operacionais. Desta forma, segundo Nguyen et al (2007) derivativos podem ser definidos como instrumentos financeiros cujos valores são oriundos de ativos, taxas ou preços e que tem por objetivo assegurar a redução de possíveis impactos no resultado e o favorecimento a permanência das empresas no mercado competitivo.

Pesquisa realizada por Araújo et al (2011) revelou-se que "a crescente utilização de instrumentos financeiros derivativos como forma de mitigar determinados riscos ao resultado da companhia, traz consigo a necessidade de melhor compreensão sobre esse tipo de operação". Neste contexto, os autores ainda afirmam que as normas contábeis facultam às empresas a utilização de contabilidade de hedge (Hedge Accounting) desde que sejam cumpridas as exigências impostas pelas normas.

Diante das exigências em relação a normatização destas operações, o FASB (Financial Accounting Standards Board) emitiu em 1998 o pronunciamento SFAS 133 - Standard Accounting for Derivative Instruments and Hedging Activities objetivando o cumprimento da regulamentação dos instrumentos derivativos. No entanto, este pronunciamento foi postergando para junho 2000 pelo SFAS 138 - Accounting for Certain Derivative Instruments ad Certain Hedging Activities - Na Amendment of FASB Statement $n^{\circ} 133$, uma vez que o SFAS 133 recebeu duras críticas devido à dificuldade de implementação.

Zani, Zanini e Zani (2010, p. 2) descrevem que "a função do derivativo financeiro é proteger a empresa [...], entretanto, esse mesmo contrato pode se tornar uma operação especulativa e gerar prejuízos não operacionais se não for corretamente gerenciado". Da mesma forma, Murcia (2009) ratifica ao afirmar que o objetivo principal das operações envolvendo derivativos é proteger as empresas contra as variações de preços (commodities), taxas de juros e câmbio, porém, a utilização destas operações de forma indevida pode acarretar em perdas para as companhias.

Segundo Rocha (2005) o registro das operações de derivativos precisa seguir uma certa coerência de confrontação entre ganhos e perdas obtidos com o ativo protegido e entre os ganhos e perdas obtidos com o instrumento de proteção (Hedge). De acordo com o autor, estes adotam posições inversas, de modo que um deles possa gerar ganho e o outra perda.

Como já mencionado anteriormente, o avanço da globalização econômica estimulou ao crescimento da competitividade em ambiente empresarial e a divulgação de informações pertinentes de forma ágil e precisa para as tomadas de decisões. De acordo com Murcia (2009) para que a contabilidade possa disponibilizar informações úteis aos seus usuários relativas as operações com derivativos, as empresas precisam adequar-se à chamada Governança Corporativa, principalmente no que se refere a grau de disclousure ou evidenciação. Neste mesmo entendimento, Brown et al (2008) reafirmam que "[...] a divulgação obrigatória é uma ferramenta de regulamentação, a qual permite aos participantes do mercado avaliarem o risco operacional".

A utilização de instrumentos derivativos está relacionado a taxa de juros e a moeda, implicando diretamente no valor que as empresas apresentam em outros países. Tais operações podem proporcionar oscilações adicionais às contas de resultados, impactando-as de forma negativa, diante de uma visão de agências de classificação de riscos, investidores e instituições de crédito (GALDI e RCGC | UFF | Niterói/RJ | V.1 | n.1 | jan-jun. 2018 | p. 59-73 
GUERRA, 2009). Os autores ainda esclarecem que muitas empresas aderem aos padrões internacionais de contabilidade, buscando atestar e consolidar os resultados.

Para um melhor entendimento sobre os instrumentos financeiros derivativos, Lima e Lopes (2001, p. 27) afirmam que elevada alavancagem; a brevidade nas transações devido ao avanço da tecnologia em terminais eletrônicos e a complexidade da estrutura das transações são mecanismos que os diferem dos demais instrumentos financeiros.

Adicionalmente, Hughen (2010) afirma que o derivativo não designado como Hedge Accounting, além de reduzir a exposição da empresa aos riscos de mercado, contribui para a redução da volatilidade e o aumento nos resultados contábeis das empresas. Porém, Smith e Stulz (1985) consideram que a redução da volatilidade nos resultados e nos fluxos de caixa podem fazer com que o valor das empresas aumente com incorreções de mercado, como por exemplo situações onde as empresas apresentam dificuldades em saldar seus compromissos financeiros.

Devido à dificuldade relacionada ao pronunciamento SFAS 133, muitas empresas antes da contratação das operações de hedge, devem estabelecer períodos de tempo onde serão alinhadas suas políticas de riscos e adequações de procedimentos. O Teste de Efetividade, nada mais é que a execução dos requisitos predeterminados antes do fechamento do contrato. Além disso, como os custos destas transações são altas, deve-se avaliar o contrato e seus benefícios, para que se possa identificar o melhor nível de maximização para o valor das empresas. Este procedimento é primordial assim como a confirmação de que as variáveis podem influenciar na escolha contábil.

Diante dos dispositivos apresentados, este trabalho responde a seguinte pergunta: Fatores como "tamanho" e "dívida" influenciam na implantação da contabilidade de hedge Accounting em empresas brasileiras de capital aberto? Através das análises dos dados será possível verificar as seguintes hipóteses:

H0: Os fatores "tamanho" e "dívida" são significativos que influenciam as empresas a adotar a metodologia do Hedge Accounting,

ou a sua alternativa:

H1: Os fatores "tamanho" e "dívida" não são significativos que influenciam as empresas a adotar a metodologia do Hedge Accounting.

A importância deste trabalho fundamenta-se principalmente em quantificar possíveis determinantes para a utilização de hedge accounting em companhias brasileiras com níveis mais elevados de governança, que são as empresas do Novo Mercado. Assim o presente trabalho vem suprir a lacuna sobre possíveis determinantes na adoção de hedge accounting para empresas com maiores níveis de governança corporativa.

A base amostral deste estudo é composta por 137 companhias de capital aberto, listadas no segmento Novo Mercado da BM\&FBOVESPA. Ainda que a amostrar seja formada por diversos setores, o objetivo aqui definido consiste em encontrar resultados que sustentem a identificação de determinantes significativos para a escolha contábil. A escolha por este segmento se deu ao fato do alto nível de governança corporativa e a alta probabilidade de identificar companhias que tenham contratado derivativos durante o exercício analisado.

Para melhor embasamento ao trabalho de pesquisa, os autores Guerra e Galdi (2009), Saito e Schiozer (2005) e Fenn, Post e Sharpe (1996) serão base para sustentar esta pesquisa, uma vez que tais autores apresentam indícios de que existem relação entre "tamanho" e "dívidas" das empresas com os instrumentos financeiros derivativos hedge.

\section{REFERENCIAL TEÓRICO}

Nas próximas seções serão apresentados a estrutura conceitua, as possíveis classificações, operacionalização das transações, efetividade do Hedge, os aspectos relacionados a contabilização e os impactos no resultado das empresas. 


\subsection{Instrumentos Financeiros Derivativos}

Instrumento financeiro têm por definição qualquer obrigação contratual onde as partes estão empenhadas em realizar transações econômicas em troca de ativos financeiros ${ }^{1}$ (Lopes, Galdi e Lima, 2011). Ainda segundo os autores, os instrumentos financeiros derivativos têm como características: a) alterações de seus valores em decorrência das variações cambiais e os preços de commodities; b) não exige quase nenhum investimento inicial; e c) seus valores serão liquidados em data futura.

Lopes e Lima (2003) classificam os instrumentos financeiros derivativos em primeira e segunda geração. A primeira geração contempla os contratos futuros, opções e a termo e swaps. Em relação a segunda geração englobam os straddle (compra de uma call e uma put pelo mesmo preço de exercício); strangel (muito similar ao straddle, porém com preço de exercício diferente), strap (compra de dois call e um put), butterfly (compra de uma call de exercício baixo, venda de duas call de exercício médio e compra de uma call de exercício baixo), condor, box (caso seja usada como futuro de índice transforma uma aplicação de renda variável em renda fixa).

A utilização dos instrumentos derivativos como mecanismo de proteção (hedge) nasceu da necessidade dos agentes econômicos em minimizar as oscilações do preço das obrigações financeiras garantindo a diminuição de resultados indesejados das empresas (Araújo et al., 2011). Darós e Alberton (2007) afirmação ainda que estes instrumentos além de proteger as operações financeiras ou operacionais contratadas para mitigar os riscos, auxiliam no processo de precificação de itens em negociação, favorecem a novas oportunidades de negócios e a contribuição para o aumento e diversificação de carteiras.

Em pesquisa realizada por Bartram, Brown e Fehle (2009) investigou-se as práticas dos instrumentos financeiros derivativos de taxa cambial, taxa de juros e preço de commodity em nível global. Através desta investigação foi possível verificar que a utilização dos derivativos está associada à alavancagem financeira, a vencimento de débitos, em investimentos em ativos líquidos e na política de dividendos para as empresas que operam em mercados de derivativos menos líquidos, especificamente em países de renda média, onde hedge são menos propensos.

Para Saito e Schiozer (2007) acerca da contratação de derivativos em empresas brasileiras não financeiras de capital aberto constatou-se que a utilização de instrumentos derivativos possuem similaridades em relação a países como Estados Unidos, Hong Kong, Cingapura e Reino Unido. Esta similaridade está relacionada as tomadas de decisão dos agentes econômicos na contratação dos derivativos com o objetivo de proteger suas posições financeiras contra riscos de mudança na política governamental de taxa de juros, diminuição dos riscos inerentes ao mercado de commodities e dos riscos cambiais

Em relação as características dos derivativos destacam-se os itens quanto a finalidade para o qual a empresa os adquiriu. Desta maneira, Lopes e Lima (2001, p. 25-41) classificam os derivativos em:

1. Hedge de uma exposição a mudanças no fair value de um ativo ou passivo já reconhecido ou de um compromisso firme ainda não reconhecido (fair value hedge);

2. Hedge de uma exposição a fluxos de caixa variáveis de uma transação futura projetada (cash flow hedging);

3. Hedge de uma exposição a uma moeda estrangeira de um investimento em uma operação internacional, um compromisso ainda não reconhecido, um título destinado à operação de trading da instituição ou uma transação esperada denominada em moeda estrangeira; e

4. Instrumentos não designados como instrumentos de hedge. Estes instrumentos são aqueles que a instituição adquiriu com o propósito de obter resultados positivos com as flutuações de preços e taxas.

\footnotetext{
${ }^{1}$ Ativos financeiros são itens de disponibilidade imediata como caixa ou dinheiro, títulos patrimoniais ou contratos de liquidação futura ou passivos financeiros que são obrigações contratuais de entregar caixa ou títulos patrimoniais
} 
Para estes autores esta classificação é de suma importância, uma vez que servem de base para orientar todo o tratamento contábil subsequente desses instrumentos.

\subsection{Aspectos Relativos a Contabilização de Hedge}

Capelletto, Oliveira e Carvalho (2007) conceituaram Hedge como uma estratégia protetiva que visa mitigar riscos associados as oscilações de preços e taxas em determinadas posições assumidas ou futuras, mediante compensação entres os resultados produzidos. A contabilização de hedge é utilizada especialmente para que as demonstrações financeiras reflitam adequadamente o regime de competência frente a realização de mecanismos de proteção (Lopes, Galdi e Lima, 2011, p. 144).

Apesar da contabilização ser um procedimento opcional para as empresas, sua utilização exige fundamentação de uma série de evidencias complexas para que não haja restrição a utilização (Lopes, Galdi e Lima, 2011). Isto porque evidencias não enquadradas à normatização (SFAS 133), descaracteriza a operação, denotando assim o possível interesse especulativo por parte da empresa (Galdi e Guerra, 2009).

Drakopoulou (2004, p. 151-165) demonstrou em sua pesquisa a maneira como os instrumentos derivativos Hedge funcionam para as empresas. Um derivativo designado como hedge de exposição a mudanças no valor justo (fair value) de um ativo ou passivo reconhecido (hedge de justo valor), os ganhos ou perdas geradas devem ser reconhecidos no resultado no período, com o objetivo de compensar perdas ou ganhos relativos ao item coberto pelo risco. Para os derivativos concebidos como cobertura a exposição as variações dos fluxos de caixa previstas (hedge de fluxo de caixa), as parcelas efetivas do ganho ou perda inicialmente deverão ser reconhecidas em rubrica de outros resultados abrangentes, classificados no grupo Patrimônio Líquido das empresas e posteriormente reclassificadas em resultados quando da sua efetivação. Por fim, o autor menciona o derivativo designado como hegde de exposição em moeda estrangeira de um instrumento líquido em operações no exterior, onde seu ganho ou perda serão classificado como outros resultados abrangentes.

Com relação as formas de contabilização com operações de hedge, Rocha (2005) em consonância com SFAS 133, esclarece que são três os tipos de classificação quanto a finalidade:

\footnotetext{
a. Fair Value Hedge - utilizado como proteção de itens patrimoniais ou de compromissos firmes não reconhecidos contra as variações de preço ocorridas no mercado. Tanto os ganhos e perdas no instrumento de hedge e no instrumento protegido afetam diretamente ao resultado da empresa;

b. Cash Flow Hedge - proteção de fluxo de caixa gerado por um ativo ou passivo. A parcela efetiva dos ganhos e perdas do hedge (aquela coberta pela operação) vai para o Patrimônio Líquido até que a transação se efetive, para, depois, ser lançada ao Resultado. A parcela não efetiva (não coberta) vai diretamente para o resultado da empresa.

c. Foreign Currency Hedge - proteção de negócios realizados em moeda estrangeira, possuindo várias modalidades. Estes procedimentos são variáveis. Algumas se aproximam ais do Fair Value Hedge, outros do Cash Flow Hedge.
}

\subsection{Operacionalização e a Efetividade do Hedge Accounting}

Instrumentos financeiros derivativos são contratos que possuem seu valor originário de um ativo base que não o próprio contrato. Ainda em acordo com os autores, estes contratos derivativos possuem as seguintes características (Lopes e Lima,2001): 
1. Possuem um ou mais ativos base e um ou mais valores nocionais ou provisão para pagamentos ou ambos. Neste caso, estes valores são base para a determinação do valor da liquidação financeira;

2. Não existe investimento líquido inicial na operação ou se existe este investimento é significativamente menor que o investimento essencial em outros contratos nos quais é aguardada uma resposta similar às oscilações nas variáveis principal de mercado; e

3. Os termos do contrato permitem ou exigem a liquidação financeira, que pode ser realizada por mecanismos fora do contrato, ou ocorre à transação ou sacrifício de um ativo que não apresente diferença significativa em relação à liquidação financeira.

Ainda em conformidade com as normas do FASB, os derivativos deverão:

1. Estar registrados nos grupos de ativos ou passivos, uma vez que representam direitos ou obrigações, dependendo da situação. Sendo assim, os registros das operações passam a existir no Balanço Patrimonial.

2. Registro dos ajustes contábeis provocados pelas variações das mensurações dos derivativos pelo fair value.

3. Os derivativos somente poderão ser contabilizados se tais instrumentos forem oriundos de operações com hedge (hedgeados).

Em sequência ao entendimento sobre as categorias de derivativos, segundo SFAS 133, as operações de hedge podem ser classificadas de acordo com a finalidade para a qual a empresa as adquiriu (Rocha, 2005). Desta maneira, podemos classificar como hedge de exposição às mudanças do fair value de ativos ou passivos já reconhecidos ou de compromissos futuros e que ainda não foram reconhecidos (Fair Value Hedge), hedge de exposição a um fluxo de caixa, onde existem diversas variáveis de uma operação futura (Cash Flow Hedging), hedge de exposição às variações cambiais de um investimento, de compromissos não reconhecidos, títulos destinado à operação de trading da instituição e por último, os instrumentos não estabelecido como instrumento de hedge, adquirido com o objetivo de gerar resultados positivos devido às oscilações de preços e taxas (hedge especulativo), (Lopes e Lima; 2001, p. 32).

Os benefícios das operações com derivativos hedge provem de procedimentos como a compensação das oscilações dos fair value do item hedge bem como a proteção contra a exposição as oscilações dos fluxos de caixa vinculados as operações com hedge. Segundo Zhang (2006, apud Galdi e Guerra, 2009) a não efetividade de hedge se caracteriza pela não cobertura à exposição aos riscos; correlacionando assim com especulação de mercado. O autor ainda conclui que existem evidencias de que o SFAS 133 restringe o uso de derivativos de hedge em caráter especulativos.

Quanto a eficácia do hedge, Drakopoulou (2014, p. 151-165) o descreve como sendo a capacidade de o instrumento derivado gerar ganhos e perdas como objetivo de neutralizar os perdas e ganhos relacionado ao item coberto (protegido). Ainda de acordo com o autor, para que o Hedge Accounting seja utilizado, a empresa deve antecipar e averiguar se o hedge será altamente efetivo na compensação de mudanças nos valores do item coberto ou mudanças em valores dos fluxos conectados ao item coberto. Após o seu reconhecimento, o hedge deve ser praticamente efetivo para que a prática do Hedge Accounting continue sendo utilizada.

Quanto a metodologia para avaliação da eficácia do Hedge, as empresas precisam selecionar um mecanismo de mensuração para medir as parcelas variáveis do valor do derivativo destinado a compensar as mudanças relativas à cobertura e a avaliação da eficácia de hedge de forma contínua enquanto houver cobertura (Trombley, 2003, p. 35). Lopes, Galdi e Lima (2011, p. 149) relatam que os métodos de teste de efetividade envolvendo operações de hedge não estão esclarecidas nas normas, porém se faz necessário a seleção e documentação do início da operação e a aplicação de maneira consistente no decorrer da operação.

Segundo pesquisa realizada por Drakopoulou (2014), em 06 de novembro de 2008, o FASB emitiu uma proposta alterando a orientação quanto a efetividade de hedge. Desta maneira, o SFAS 133 não mais exigiria: a) que uma relação de cobertura seja altamente efetiva, b) uma relação quantitativa avaliação da eficácia de uma relação de cobertura, ou c) teste de eficácia contínua. De RCGC | UFF | Niterói/RJ | V.1 | n.1 | jan-jun. 2018 | p. 59-73 
acordo com o autor, através destas mudanças a relação de cobertura deve ser "razoavelmente eficaz" e não mais "altamente efetiva", o que deixou as mais simples para as entidades executar regularmente Hedge Accounting e fornecer comparabilidade e uniformidade nos resultados das demonstrações financeiras.

Com relação ao disclosure das informações relativas às operações de Hedge Accounting, Martins et al (2013, p. 153) esclarecem que o processo de descontinuidade destas operações ocorre quando estas se tornam desnecessárias (operações vencidas, transferência dos riscos e benefícios relacionados a transação com terceiros, alienação ou outra forma de transação estruturada) devendo ser baixadas do Balanço Patrimonial.

\subsection{Hedge Accounting Segundo os IFRS}

A partir da adoção dos IFRS, passou-se então, no Brasil, a abandonar o uso do SFAS 133 com o fim de convergir-se para o padrão contábil dos IFRS. Nesta seção detalharemos o IFRS 9, que trata sobre Hedge Accounting.

O IAS 39 foi substituído pelo IFRS 9, que manteve as 3 classificações anteriores do IAS 39: Fair Value Hedge, Cash Flow Hedge e Hedges of Net Investments in Foreign Operations, equivalente ao antigo Foreign Currency Hedge. Assim como o SFAS 133 e o IAS 39, o IFRS 9 ainda traz a opcionalidade do uso de hedge accounting, portanto o presente estudo ainda é pertinente, mesmo com a mudança do padrão normativo, visto que a escolha ainda é opcional.

Não houve mudanças nos tipos de itens que são elegíveis para o uso de hedge accounting do IAS 39 para o IFRS 9, porém houve a criação da distinção entre estratégia de gerenciamento de risco com o objetivo do gerenciamento de risco. A primeira é um delineamento geral das políticas da entidade sobre o seu gerenciamento de risco, enquanto a segunda está relacionado com o objetivo específico de um item, ou grupo de itens, que estão sendo contabilizados segundo hedge accounting.

Assim sendo, o IFRS 9 deu mais flexibilidade às entidades para poderem contabilizar os instrumentos financeiros segundo o hedge accounting, utilizando uma normativa menos estrita e restritiva, como era o IAS 39 e o SFAS 133.

\section{METODOLOGIA}

\subsection{Escolha da Amostra e Coleta de Dados}

Este trabalho pode ser caracterizado, de acordo com os objetivos, como descritivo, pois estabelece relações entre diferentes variáveis, tendo por objetivos correlaciona-las e descrevê-las. A ipesquisa descritiva tem por objetivo descrever as características de determinadas populações ou possíveis fenômenos (Gil, 2008). Classifica-se ainda como quantitativo uma vez que serão realizados testes estatísticos, com o intuito de medição no grau de interação entre as variáveis.

Realizou-se para esta pesquisa a escolha de sociedades por ações de capital aberto que tiveram os seus demonstrativos financeiros e notas explicativas publicadas no site da BM\&FBOVESPA, no segmento Novo Mercado durante o exercício de 2016. Nós escolhemos o Novo Mercado como base amostral devido à nossa questão de pesquisa descrita na introdução onde verificamos possíveis determinantes para a adoção de hedge accounting por empresas brasileiras com níveis de governança mais elevados, que estão listadas na bolsa de valores.

Das 137 companhias listadas, somente 91 (66,42\% da amostra), compõem a base amostral para estudo (Tabela 1). A principal intenção foi alcançar resultados plausíveis e consistentes que pudessem contribuir para a identificação de variáveis que exerçam influência sobre a escolha da metodologia contábil para as operações envolvendo contabilização do Hedge (Hedge Accounting SFAS 133) utilizando a inferência. 
Os critérios utilizados para a seleção da amostra contaram com os seguintes fatores: a. Identificação das companhias listadas no segmento Novo Mercado, no site da BM\&FBOVESPA que tiveram seus demonstrativos financeiros de 2016 publicados; b. Análise das notas explicativas objetivando a identificação de contratos ativos de instrumentos derivativos durante o exercício em análise; c. Identificar as companhias que apresentaram transações financeiras ou operacionais envolvendo moeda estrangeira; e d. Segregação entre as companhias que mencionaram a utilização do Hedge Accounting (Tabela 1).

Diferente deste estudo, Galdi e Guerra (2009), consideraram em sua análise as notas explicativas dos relatórios anuais de 2006 das companhias listadas na New York Stock Exchange objetivando a identificação de operações envolvendo Hedges, mas, porém, foram desconsideradas de sua base todas as companhias que não especificaram a utilização do Hedge Accounting ou mencionaram não efetividade, ou não relataram a efetividade de seus testes.

Tabela 1: Seleção dos dados

Companhias de capital aberto listadas na BM\&BOVESPA entre 01/01/2016 e 31/12/2016:

( - ) Companhias que não apresentaram informações de contratos ativos de instrumentos derivativos durante exercicio de 2016:

( = ) Número de companhias contratos ativos de instrumentos derivativos:

\subsection{Definição das Variáveis}

Após a escolha da amostra e a coleta dos dados, foi definido como metodologia de análise o modelo logist, onde foram estabelecidas variáveis independentes categorias e não categorias as quais serão utilizadas para a formulação do modelo. As variáveis dependentes foram formuladas tendo por base a existência ou não de Hedge Accounting, isto é, 0 para as companhias que não mencionaram a utilização do Hedge Accounting e 1 para as companhias que mencionaram a sua adoção. Os dados foram tabulados e organizados conforme Tabela 2. 
Tabela 2: Lista das variáveis usadas no estudo

\begin{tabular}{|c|c|c|}
\hline Variáveis & Proxies & Natureza \\
\hline $\begin{array}{l}\text { y= não utilização Hedge } \\
\text { Accounting ou utilizam Hedge } \\
\text { Accounting }\end{array}$ & $\begin{array}{l}\text { - Não utilizam Hedge Accounting = } 0 \\
\text { - Utilizam Hedge Accounting }=1\end{array}$ & $\begin{array}{l}\text { Variável } \\
\text { Dependente } \\
\text { Qualitativa }\end{array}$ \\
\hline $\mathrm{ptd} \times 1$ & $\begin{array}{l}\text { = Preço das Ações no Fechamento/Lucro Líquido } \\
\text { (Price-to-Book - PTB) }\end{array}$ & $\begin{array}{l}\text { Independente } \\
\text { Quantitativa }\end{array}$ \\
\hline Fatatx2 & = Faturamento/Ativo Total & $\begin{array}{l}\text { Independente } \\
\text { Quantitativa }\end{array}$ \\
\hline Divcatx3 & = Dívida de Curto Prazo/Ativo Total & $\begin{array}{c}\text { Independente } \\
\text { Quantitativa }\end{array}$ \\
\hline Divlatx4 & = Dívida de Longo Prazo/Ativo Total & $\begin{array}{c}\text { Independente } \\
\text { Quantitativa }\end{array}$ \\
\hline Luatx5 & $=$ Lucro Bruto/Ativo Total & $\begin{array}{c}\text { Independente } \\
\text { Quantitativa }\end{array}$ \\
\hline Dummy_tesefetx7 & $\begin{array}{l}\text { = Dummy de Teste de efetividade, onde: } \\
\text { - Não realiza teste de efetividade }=0 \\
\text { - Realiza teste de efetividade }=1\end{array}$ & $\begin{array}{c}\text { Independente } \\
\text { Quantitativa }\end{array}$ \\
\hline Dummy_audbfourx6 & $\begin{array}{l}\text { = Dummy auditadas por Big Four, onde: } \\
\text { - Não auditada por Big Four }=0 \\
\text { - Auditada por Big Four }=1\end{array}$ & $\begin{array}{l}\text { Independente } \\
\text { Quantitativa }\end{array}$ \\
\hline Dummy_fatestrx8 & $\begin{array}{l}\text { = Dummy Faturamento em Moeda Estrangeira, onde: } \\
\text { - Não possui faturamento em Moeda Estrangeira = } 0 \\
\text { - Possui faturamento em Moeda Estrangeira = } 1\end{array}$ & $\begin{array}{c}\text { Independente } \\
\text { Quantitativa }\end{array}$ \\
\hline Dummy_divestrx9 & $\begin{array}{l}\text { = Dummy Dívida em Moeda Estrangeira, onde: } \\
\text { - Não possui dívida em Moeda Estrangeira = } 0 \\
\text { - Possui dívida em Moeda Estrangeira = } 1\end{array}$ & $\begin{array}{c}\text { Independente } \\
\text { Quantitativa }\end{array}$ \\
\hline
\end{tabular}

A segregação e organização dos dados foram estruturando com o objetivo de utilização do modelo de regressão logist; que segundo Hair Jr. et al. (2009, p. 34) "é a técnica multivariada adequada para uma única variável dependente é dicotômica". Dias Filho e Corrar (2009) sustentam que "[...] além de possibilitar a classificação dos fenômenos ou indivíduos em categorias específicas, a regressão logística tem ainda por objetivo estimar a probabilidade de ocorrência de determinado evento ou de que um fenômeno venha a se enquadrar nessa ou naquela categoria". Desta maneira, os resultados gerados pelas variáveis dependentes devem motivar a interpretações em termos de probabilidade e não somente a classificação categórica.

Deste modo, através da probabilidade estatística, tem se o objetivo buscar estimar a associação da variável dependente qualitativa e dicotômica com as variáveis independentes que estão associadas com o "tamanho" e a "dívida" das companhias. Sendo assim, a regressão logística se apresenta como a técnica estatística adequada para analisar as variáveis classificatórias evidentes na amostra. Abaixo segue o modelo de regressão logist. estabelecido:

$$
\begin{aligned}
& y=60+\text { 61.ptdx } 1+\text { 62.fatal } x 2+\text { 63.divcat } x 3+\text { 64.divlat } 4+\text { 65.luat } x 5+\text { 66.dummy_tesfetx } 6+ \\
& + \text { 67.dummy_audbfourx } 7+68 . d u m m y \text { fatestrx } 8+69 . d u m m y \_d i v e s t r x 9+\varepsilon
\end{aligned}
$$

O modelo de regressão logística foi composta com as seguintes variáveis: Y que está relacionado com a escolha adotada pela companhia no que se refere à contratação e qualificação das operações envolvendo dos derivativos de Hedge; ptdx 1 é o índice price-to-book; fatalx2, divcatx3 e divilatx4 estão relacionados com "tamanho" e "dívida" das companhias; luatx 5 está relacionado ao lucro bruto que também remete ao "tamanho" das companhias; dummy_fatestrx 8 e dummy_divestrx 9 estão relacionados a faturamento e dívidas em moeda estrangeira, cujos Hedge são contratados com o objetivo de proteção contra a variação cambial; dummy_audbfourx7 é uma variável relacionada a RCGC | UFF | Niterói/RJ | V.1 | n.1 | jan-jun. 2018 | p. 59-73 
contratação de "Big Four"; dummy_tesfetx6 relacionada com o teste de efetividade relacionadas a empresas que buscam atender as normas do FASB e $\varepsilon$ é o termo de erro para as companhias.

Através desta equação de regressão logist anseia-se constatar a relação direta entre o "tamanho" e "dívida" das companhias com a escolha contábil relacionadas a operações com Hedge, demonstrando assim a relação entre a instabilidade na variação cambial e nas taxas de juros, bem como no tamanho das empresas, conforme pesquisas realizadas por Saito e Schiozer (2005, p. 97107) e Galdi e Guerra (2009).

\section{ANÁLISE DOS RESULTADOS}

Nos tópicos à frente serão apresentados os resultados e as análises gerados pela regressão logist com o objetivo de responder à questão levantada por este estudo: "tamanho" e "dívida" são fatores que influenciam a utilização do Hedge Accounting nas companhias brasileiras?

\subsection{Resultados}

Para a validação da eficácia do modelo utilizado, foi necessário testar e identificar relações significativas que possam estatisticamente explicar as ocorrências dos eventos. Desta maneira, Galdi e Guerra (2009) descrevem que "[...], os testes de significância são importantes, pois permitem a verificação da acuracidade das predições desejadas".

Tabela 3: Estatística descritiva das variáveis

\begin{tabular}{|c|c|c|c|c|c|c|c|}
\hline Variáve is dependentes & Média & Mediana & Mínimo & Desvio Padrão & Variância & $\mathbf{N}^{0}$ Amostra & Máximo \\
\hline $\begin{array}{l}\text { Utiliza Hedge Accounting x } \\
\text { Não Utiliza Hedge }\end{array}$ & 0,3556 & 0 & 0 & 0,4814 & 0,2317 & 91 & 1 \\
\hline Variáve is Independentes & Média & Mediana & Mínimo & Desvio Padrão & Variância & $\mathbf{N}^{0}$ Amostra & Máximo \\
\hline ptdx1 & 99,8401 & 52,2216 & $-13,5155$ & 132,8850 & 17658,4262 & 91 & 628,1860 \\
\hline Fatatx2 & 0,6678 & 0,5782 & 0,0006 & 0,5105 & 0,2606 & 91 & 3,2017 \\
\hline Divcatx3 & 0,3011 & 0,2415 & 0,0430 & 0,2081 & 0,0433 & 91 & 1,2486 \\
\hline Divlatx4 & 0,3559 & 0,3109 & 0 & 0,3538 & 0,1252 & 91 & 2,5266 \\
\hline Luatx5 & 0,1973 & 0,1668 & $-0,1560$ & 0,1798 & 0,0323 & 91 & 1,0039 \\
\hline Dummy tesefetx6 & 0,1778 & 0 & 0 & 0,3845 & 0,1478 & 91 & 1 \\
\hline Dummy_audbfourx 7 & 0,9000 & 1 & 0 & 0,3017 & 0,0910 & 91 & 1 \\
\hline Dummy_fatestrx8 & 0,2111 & 0 & 0 & 0,4104 & 0,1684 & 91 & 1 \\
\hline Dummy divestrx9 & 0,2778 & 0 & 0 & 0,4504 & 0,2029 & 91 & 1 \\
\hline
\end{tabular}

Na Tabela 3 é apresentada a estatística descritiva das variáveis selecionadas para este estudo onde verifica-se uma aproximação entre as medianas não categóricas (fatatx2, divicatx3, divlatx4 $e$ luatx5) e suas respectivas médias. Isto denota uma certa normalidade na distribuição, diferente da variável ptbxl que apresentou irregularidade na sua distribuição (média, mediana relativamente distantes).

Como forma de avaliar a eficácia do modelo adotado, foi utilizado o modelo Chi-Square (ou teste qui-quadrado) que serve para avaliar estatisticamente a relação entre os coeficientes produzidos e a distribuição amostral. Para este modelo ajustado, o nível de significância das variáveis assumidas no modelo foi de aproximadamente $80 \%$, ao nível de significância de 5\%. Desta maneira, os coeficientes são significativos para explicar a adoção da escolha contábil para as companhias da amostra. Ao analisar o nível de significância dos parâmetros, verificou-se que os valores associados ao p-valores das variáveis "faturamento" e "dívida", apresentaram resultados significativos não rejeitando a hipótese nula. (H0>p-valor). 
Baseando-se na estatística teste Wald, que consiste em um teste utilizado para avaliar se os parâmetros são estatisticamente significativos, apresenta-se na Tabela 2 os resultados gerados. Verifica-se que todos os resultados gerados foram diferentes de zero, rejeitando desta maneira a H0. O resultado apresentado no estudo conduzido por Galdi e Guerra (2009) ratifica os resultados aqui apresentados, uma vez que os resultados apresentados pelos autores foram nulos e rejeitados pela $\mathrm{H} 0$. Os resultados não diferentes de zero, rejeitando a hipótese nula e que reforça a utilização das variáveis.

Tabela 4: Resultado Regressão Logit (utiliza hedge accounting x não utiliza hedge accounting)

\begin{tabular}{l|l|r|r|r|r}
\hline $\begin{array}{c}\text { Variáve is } \\
\text { inde pendentes }\end{array}$ & $\begin{array}{c}\text { Sinais } \\
\text { espe rados }\end{array}$ & Coeficientes & P-valor & $\begin{array}{c}\text { Desvio } \\
\text { Padrão }\end{array}$ & Wald \\
\hline ptdx1 & - & 0,0001 & 0,7201 & 0,0002 & 0,1293 \\
\hline Fatatx2 & + & 0,0756 & 0,1989 & 0,0584 & 1,6781 \\
\hline Divcatx3 & + & $-0,1613$ & 0,1453 & 0,1097 & 2,1634 \\
\hline Divlatx4 & + & $-0,0220$ & 0,6100 & 0,0429 & 0,2623 \\
\hline Luatx5 & + & $-0,1082$ & 0,2751 & 0,0985 & 1,2079 \\
\hline Dummy_tesefetx7 & $?$ & 0,1081 & 0,4938 & 0,1572 & 0,4726 \\
\hline Dummy_audbfourx6 & - & 0,0728 & 0,2045 & 0,0569 & 1,6364 \\
\hline Dummy fatestrx8 & + & 0,3916 & 0,0046 & 0,1344 & 8,4938 \\
\hline Dummy_divestrx9 & + & 0,6513 & 0,0000 & 0,1026 & 40,3090 \\
\hline
\end{tabular}

Os resultados apresentados na Tabela 4 foram capazes de demonstrar as escolhas das companhias quanto a utilização ou não da metodologia de contabilização do Hedge (Hedge Accounting). Para a variável fatatx2 (faturamento), que é uma variável que está relacionada diretamente com o tamanho da companhia, a análise apresentou coeficiente positivo, corroborando com as considerações apresentadas por Saito e Schiozer (2005) e Galdi e Guerra (2009) de que "existe economia de escala para o uso de derivativos". Porém, o coeficiente luatx 5 que está associado ao lucro bruto das companhias, apresentou resultado inversamente esperado, o que pode estar associado as questões dos custos dos produtos e serviços gerados das companhias.

Com relação as variáveis divcatx3 e divlatx4 que estão relacionadas as dívidas de curto e longo prazo respectivamente, os resultados (coeficientes negativos) não apresentaram relação com os resultados apresentados por DeMarzo e Duffie (1995) e Saito e Schiozer (2005), onde, apesar das taxas de juros ser uma das principais fontes de volatilidade, não são considerados como item que possam influenciar na escolha contábil. No entanto, o comportamento conservador das companhias pode estar relacionado com a alta expectativa de volatilidade das taxas de juros e a grande oscilação da variação cambial, fazendo com que as companhias busquem outras formas de capital.

Para o coeficiente $p t d x 1$ (Price-to-book), que está relacionado ao lucro bruto das companhias, foi apresentado coeficiente positivo atestando a relação com a variável dependente. Na pesquisa realizada por Galdi e Guerra (2009) o resultado positivo do coeficiente confirmou que quanto maior o coeficiente, menor será o risco e a probabilidade de as companhias contratarem operações envolvendo derivativos e a qualificação dos instrumentos como Hedge Accounting.

Com relação a variável dummy_audbfourx6 (relacionadas a companhias auditadas por Big Four) o resultado apresentado na tabela foi positivo e inversa ao resultado esperado. Desta maneira, em acordo com os resultados apresentados por Pereira et al. (2017), as companhias que são auditadas por Big Four, não são propensas ao cumprimento aos altos níveis de exigências para avaliação dos processos envolvendo Hedge Accounting. 
Tabela 5: Efeitos sobra a probabilidade de resposta

\begin{tabular}{|c|c|c|c|}
\hline $\begin{array}{c}\text { Variáveis } \\
\text { inde pende ntes }\end{array}$ & Coeficientes & Wald & $\begin{array}{c}\text { Aproximação } \\
\text { Logit - b x 0,25 }\end{array}$ \\
\hline ptdx1 & 0,0001 & 0,1293 & $0,002 \%$ \\
\hline Fatatx2 & 0,0782 & 1,6781 & $1,955 \%$ \\
\hline Divcatx3 & 0,1544 & 2,1634 & $-3,860 \%$ \\
\hline Divlatx4 & 0,0131 & 0,2623 & $-0,326 \%$ \\
\hline Luatx 5 & 0,0984 & 1,2079 & $-2,460 \%$ \\
\hline Dummy_tesefetx6 & 0,1083 & 0,4726 & $2,707 \%$ \\
\hline Dummy audbfourx7 & 0,0898 & 1,6364 & $2,246 \%$ \\
\hline Dummy fatestrx8 & 0,3914 & 8,4938 & $9,785 \%$ \\
\hline Dummy divestrx9 & 0,6528 & 40,3090 & $16,320 \%$ \\
\hline
\end{tabular}

De acordo com a Tabela 5 os valores dos coeficientes gerados referentes as variáveis dummy_divestrx 9 e dummy_fatestrx 8 , apresentaram como resultados 0,1628 e 0,09790 (seguindo a regra de aproximação $\beta=0,25$ ) respectivamente. Para melhor interpretação dos dados, utilizou-se o estudo de Galdi e Guerra (2009), onde os resultados apresentados tenderam a zero, podendo ser entendido, levando-se em consideração ao faturamento e as dívidas em moeda estrangeiras e mantendo as demais variáveis constantes, não existem fortes probabilidades para que as companhias adotarem o Hedge Accounting.

\section{CONCLUSÕES}

Esta pesquisa teve por objetivo analisar os demonstrativos financeiros das companhias de capital aberto do segmento Novo Mercado, listadas na BM\&FBOVESPA, durante o exercício de 2016, objetivando não apenas contribuir para literatura acadêmica, como também para o mercado e reguladores interessados no comportamento das companhias com relação a escolha contábil adotadas para Hedge (Hedge Accounting).

Para o desenvolvimento desta pesquisa foram selecionados trabalhos que utilizaram variáveis explicativas que pudessem contribuir para a análise comportamental de gestores nas tomadas de decisão. Desta maneira, foram escolhidas variáveis que estivessem associadas ao "tamanho" e a "dívida" das companhias, com o objetivo de verificar a relação entre elas e a escolha contábil para derivativos conhecida como Hedge Accounting. Procedimento estatístico como regressão logist foi utilizada devido a existência de variáveis dependentes e dicotômicas que assumiram valores de 0 ou 1.

Através dos resultados observados das variáveis relacionadas às dívidas de curto e longo prazo, os testes apontaram para evidencias que demonstram uma certa cautela das companhias em contrair dívidas associadas a moeda estrangeira ou a alta taxas de juros. Desta maneira, os resultados não foram capazes de predizer se as variáveis escolhidas influenciam na escolha contábil de Hegde devido ao momento especulativo vivido.

Em relação a análise das variáveis estabelecidas para a presença de Big Four, em pesquisas realizadas por Galdi e Guerra (2009) objetivou-se que companhias norte-americanas auditadas por estas empresas sofrem um alto grau de exigência nos processos de qualificação de operações envolvendo a contabilidade de Hedge. Porém, o coeficiente positivo apresentado nesta pesquisa, demonstrou estatisticamente que as Big Four não apresentam tanta influência assim no que se refere a atividade relacionadas a Hedge Accounting para as companhias brasileiras.

Para futuros trabalhos, sugere-se estudos relacionados a influência das empresas de auditoria nas companhias brasileiras, uma vez que verificou se que as auditorias, mesmo apresentando alto nível de exigências, não são capazes de influenciar as companhias na escolha contábil para operações envolvendo Hedge. Sugere-se ainda trabalhos relacionados a instrumentos financeiros derivativos adotados em companhias brasileiras de capital fechado, com o objetivo entender o comportamento RCGC | UFF | Niterói/RJ | V.1 | n.1 | jan-jun. 2018 | p. 59-73 
de empresas que não passam por rigorosas auditorias e fiscalizações. Além disso, pode-se também aumentar a base amostral para futuros estudos.

\section{REFERÊNCIAS}

ARAUJO, C. G.; IKUNO, L. M.; PAULO, E., \& SALES, I. C. H. Hedge accounting: Análise da extensão de sua utilização nas empresas brasileiras que compõem o IBRX-100. In: $11^{\circ}$ Congresso USP de Controladoria e Contabilidade, São Paulo, 2011.

BARCEDO, C. H.; ARAUJO, G. S.; LION, O. M. B. Mercado de derivativos no Brasil: Conceitos, operações e estratégias. 3 Ed. Record: Rio de Janeiro, 2009.

BARTRAM, S. M.; BROWN, G. W.; FEHLE, F. R. International evidence on financial derivatives usage. Journal Financial Management, University of Warwick Publications service \& WRAP, v. 38 n. 1, p. 185-206, 2009.

BROWN, S.; GOETZMANN, W.; LIANG, B.; SCHWARZ, C. Mandatory disclosure and operational risk: Evidence from hedge fund registration. The Journal of Finance, v. LXIII, n. 6, p. 2.785-2.815, dec. 2008 .

CAPELLETTO, L. R.; OLIVEIRA, J. L. DE; CARVALHO, L. N. Aspectos do hedge accounting não implementados no Brasil. Revista de Administração, São Paulo, v. 42, n. 4, p. 511-523, out./nov./dez. 2007.

COMITÊ DE PRONUNCIAMENTOS CONTÁBEIS (CPC). CPC 14 - Instrumentos financeiros. 2008. Disponível em: http://www.cpc.org.br, acesso em 25 de junho de 2017.

COMITÊ DE PRONUNCIAMENTOS CONTÁBEIS (CPC). CPC 38 - Instrumentos financeiros: Reconhecimento e mensuração. 2009. Disponível em: http://www.cpc.org.br, acesso em 25 de junho de 2017.

COMITÊ DE PRONUNCIAMENTOS CONTÁBEIS (CPC). CPC 39 - Instrumentos financeiros: Apresentação. 2009. Disponível em: http://www.cpc.org.br, acesso em 25 de junho de 2017.

COMITÊ DE PRONUNCIAMENTOS CONTÁBEIS (CPC). CPC 40 - Instrumentos financeiros: Evidenciação. 2009. Disponível em: http://www.cpc.org.br, acesso em 25 de junho de 2017.

DARÓS. L. L.; ALBERTON, L. A estrutura das demonstrações contábeis permite evidenciar operações com instrumentos financeiros derivativo? Uma análise dos relatórios contábeis publicados no Brasil e nos Estados Unidos. In: Congresso USP de Contabilidade e Controladoria, 7, 2007 São Paulo. Anais... São Paulo: USP, 2007.

DEMARZO, P. M.; DUFFIE. Corporate incentives for hedging and hedge accounting. The Review of Financial Studies, v. 8, n. 3, p. 743-771, 1995.

DIAS FILHO, J. M.; CORRAR, L. J. Regressão Logística. In: CORRAR, L.J.; PAULO, E.; DIAS FILHO, J. M. (Coord.). Análise multivariada: Para cursos de administração, ciências contábeis e economia. FIPECAFI - Fundação Instituto de Pesquisas Contábeis, Atuariais e Financeiras; São Paulo: Atlas, 2009.

DRAKOPOULOU, V. Accounting for derivative instruments and hedging activities. Journal of Financial Risk Management, v. 3, p. 151-165, 2014.

FASB. Financial Accounting Standards $\mathbf{N}^{\mathbf{0}} \mathbf{1 3 3}$ - Accounting for derivatives instruments and hedging activities. Disponível em: http://www.fasb.org. Acesso em 26 de junho de 2017.

FENN, G.; POST, M.; SHARPE, S. Debt maturity and the use of interest rate derivatives by nonfinancial firms. Capital Markets Section Federal Reserve Board paper, 1996. 
GALDI, F. C.; GUERRA, L. F. G. Determinantes para utilização de hedge accounting: Uma escolha contábil. Revista de Educação e Pesquisa em Contabilidade, 2009, v. 3, n. 2, p. 23-44. Disponível em: www.repec.org.br/index.php/repec/article/view/66. Acesso em 23 de junho de 2017.

GIL, A. C.; Métodos e técnicas de pesquisa social. 6 Ed. São Paulo: Atlas, 2008.

HAIR JR., J. F.; BLACK. W. C.; BABIN, B. J.; ANDERSON, R. E.; TATHAM, R. L. Análise multivariada de dados. Porto Alegre: Bookman, p. 688, 2009.

HUGHEN, L. When do accounting earnings matter more then economic earnings? Evidence from hedge accounting restatements. Journal of Business Finance \& Accounting, v. 37, n. 9 e 10, p. 1.027-1.056, nov./dez. 2010.

LOPES, A. B.; GALDI, F. C.; LIMA, I. S. Manual de contabilidade e tributação de instrumentos financeiros e derivativos. Atlas: São Paulo, 2011.

LOPES, A. B.; LIMA, I. S. Perspectivas para a pesquisa em contabilidade: O impacto dos derivativos. Revista Contabilidade \& Finanças FIPECAFI/FEA-USP, v. 15, n. 26, p. 25-41, mai./ago. de 2003.

MARTINS, E.; GELBCKE, E. R.; SANTOS, A.; IUDÍCICUS, S. Manual de contabilidade societária aplicável a todas as sociedades. 2 Ed. Atlas: São Paulo, 2013.

MARTINS, J. A. S; TOLEDO, J. R. A utilização de hedge pelas empresas brasileiras listadas no segment novo mercado da BM\&FBOVESPA. Revista Cesumar - Ciências Humanas e Sociais Aplicadas, v. 18, n. 2, p. 375-395, 2003.

NGUYEN, H.V.; MENSAH, M. O.; FAN, Y. Derivative instruments and their use for hedging by U.S. non-financial firms: A review of theories and empirical evidence. Journal of Applied Business and Economics, v. 7, n. 2, p. 35-57, 2007. Acessível em: http://ssrn.com/abstract=1082932.

MURCIA, F. D. Fatores determinantes do nível de disclosure voluntário de companhias abertas no Brasil. 2009 182f. Tese (Doutorado em Ciências Contábeis) - Faculdade de Economia, Administração e Contabilidade, Universidade de São Paulo, São Paulo, 2009.

PADOVEZE, C. L.; BENEDICTO, G. C.; LEITE, J. S. J. Manual de contabilidade internacional - IFRS - US Gaap - BR Gaap - Teorias e práticas. CENGAGE Learning: São Paulo, 2013.

ROCHA, F. D. A Contabilização das operações de hedge: Uma análise teórica e prática. II Simpósio de Excelência em Gestão e Tecnologia - SEGeT'2005. Disponível em: www.aedb.br/seget/artigos2005.php. Acesso em 24 de junho de 2017.

SAITO, R.; SCHIOZER, R. Uso de derivativos em empresas não-financeiras listadas em bolsa no Brasil. RAUSP - Revista de Administração, São Paulo, 42, p. 97-107, 2007.

SMITH, C. W.; STULZ, R. M. The determinants of firm's hedging policies. The Journal of Financial and Quantitative Analysis. University of Washington School of Business Administration, v. 20, n. 4, p. 391-405, 1985.

TROMBLEY, A. M. Accounting for derivatives and hedging, McGraw-Hill Higher Education, 2003, p. 35 .

ZHANG, $\mathrm{H}$. Effect of derivative accounting rules on corporate risk management behaviour. Ohio State University paper, 2006.

ZANI, T. B.; ZANINI, F. A. M.; ZANI, J. Governança corporativa e conflito de agência: Estudo de caso sore a utilização de derivativos cambiais por cinco grandes empresas brasileiras. In: Encontro Nacional e Pós-Graduação e Pesquisa em Administração, 34, 2010, Rio de Janeiro, Anais ...Rio de Janeiro: EnANPAD, 2010. 


\section{SOBRE OS AUTORES}

VANDO DA CONCEIÇÃO ROSAS é mestrando em Ciências Contábeis/UERJ, pós graduado em Controladoria e Finanças/Mackenzie RJ e graduado em Ciências Contábeis/UFRJ.

E-mail: vando.contabeis@ig.com.br

RODRIGO DE OLIVEIRA LEITE é mestre em Administração/EBAPE-FGV e graduado em Ciências Contábeis/UERJ. É Professor Assistente na FAF/UERJ.

E-mail: rodrigo.de.oliveira.leite@gmail.com

GUILHERME TEIXEIRA PORTUGAL é doutor em Ciências da Engenharia/UFRJ, mestre em Ciências Contábeis/UFRJ, pós graduado em Finanças/PUC-Rio e graduado em Administração de Empresas/PUC-Rio. Professor Adjunto da FAF/UERJ lecionando no programa stricto senso em Ciências Contábeis, sendo atualmente o coordenador do curso.

E-mail: teixteix@hotmail.com 